\title{
Perceived Spirituality, Mindfulness and Quality of Life in Psychiatric Patients
}

\author{
João P. Da Silva ${ }^{1}$ Anabela M. S. Pereira'
}

(C) Springer Science+Business Media New York 2016

\begin{abstract}
There is some evidence of the relationship between spirituality and quality of life, but there are few bibliographic references on these constructs for patients suffering from mental illness; thus, this study was aimed at revealing the possible role of spiritual outlooks as a protective factor in these individuals. The sample consisted of 96 Portuguese psychiatric patients, selected from a psychiatric hospital and assessed based on parameters for quality of life, spirituality and mindfulness. The data support some theories about the nature of the spirituality. Spiritual beliefs are poorly correlated with the quality of life index, and there is a moderate association between these beliefs and some aspects of mindfulness. It is suggested that a spiritual outlook of psychiatric patients should be taken into account in psychological interventions.
\end{abstract}

Keywords Psychology $\cdot$ Spirituality $\cdot$ Quality of life $\cdot$ Mindfulness $\cdot$ Psychiatric disorders

\section{Introduction}

There is currently a growing interest in subjects related to spirituality and an increase in socalled spiritual practices (e.g. yoga, meditation and reiki). Therefore, it is reasonable that spiritual matters also fall within a psychological scope. An example of this is the creation of Division 36 of the American Psychological Association (APA) - the Society for the Psychology of Religion and Spirituality—or the Spirituality and Psychiatry Special Interest Group (SPSIG) of the Royal College of Psychiatrists. The latter (SPSIG) aims to promote an integrated clinical approach, for routine use in psychiatric assessments, with an emphasis on spiritual issues (Culliford and Eagger 2009).

João P. Da Silva

jp.dasilva@outlook.com

Anabela M. S. Pereira

anabelapereira@ua.pt

1 Department of Education, University of Aveiro, Campus de Santiago, 3810-193 Aveiro, Portugal 
Spirituality has been widely studied in a number of areas such as in chronic disease (e.g. Delgado 2007; Meneses et al. 2013; Rowe and Allen 2004) and mourning (e.g. Damianakis and Marziali 2012; Wortman and Park 2009). Although there are several sources covering mental health issues and spiritual practices, most of them present speculative hypotheses and there is a lack of empirical evidence in the scientific literature to establish a relationship between spirituality and mental health.

\section{Quality of Life and Mental Health}

When looking to characterise a human being's living conditions, the quality of life (QoL) index is employed, which is usually seen as a multidimensional concept and is defined as the perception that a particular individual has of its position in life, in a cultural context with a defining value system and/or given a personal value system, as a function of its goals, expectations and concerns (WHOQOL Group 1998). The QoL domains should be cross-cultural and are usually assessed as: physical; psychological; level of independence; social relationships; environment; and spirituality/religion/personal beliefs (WHOQOL Group 1998).

Mental illness is challenging and impacts on the personal life of an individual-in particular on their QoL. People with psychopathological symptoms may experience cognitive difficulties regularly in assessing their subjective QoL, which can hinder its proper assessment (Oliver et al. 1997). Nonetheless and according to several studies, there is evidence linking QoL to good mental health scores. Hodgson et al. (2007) conducted a study in which they sought to uncover the relationship between the quality of life domains and the psychopathological picture. The study had 129 psychiatric patients as participants, assessed using the WHOQOL-BREF and the CSQ-8 instruments. It was found that certain WHOQOL-BREF domains are more sensitive to the influence of psychiatric disorders than others as well as to a personal sense of satisfaction (Hodgson et al. 2007). These results are consistent with the information obtained by Masthoff et al. (2006) showing that psychiatric patients score significantly worse in all domains of QoL than people without psychological issues. In turn, a study by Goppoldova et al. (2008), which sought to discover the specific disease profiles of psychiatric patients linked to subjective QoL, confirms the aforementioned information, stating that some psychological mechanisms of specific psychiatric conditions affect subjective QoL. Similarly, a systematic review of qualitative research on QoL and mental health in people with psychiatric problems shows that a poor QoL is related to severe psychiatric symptoms, and highlights important aspects of this relation such as well-being/malaise, control, autonomy/choice, self-perception, a feeling of belonging, activity and hope/hopelessness (Connell et al. 2012).

\section{Mindfulness and Mental Health}

Mindfulness is a fairly recent concept in psychology and psychotherapy, despite its origin being an ancient one. Mindfulness is reported as the result of meditation practices aimed at experiencing a state of complete awareness and acceptance of the present moment (Brown et al. 2013; Kabat-Zinn 2012; Slade 2010). We can say that it is an altered state of mindan unusual state-and it is believed, following Mace (2008), that this state implies a rearrangement of perceptual experiences. 
The psychophysiology of mindfulness practices has been studied since the second half of the twentieth century (e.g. Glueck and Stroebel 1975; Wallace 1970; Wallace and Benson 1972), and there is evidence for changes in brain activity as a result of meditation. Consequently, initiatives have been taken to create a clinical meditation technique. The first iteration (and the most complete) of clinical technique based on meditation was created by clinical psychologist and psychotherapist Patricia Carrington (cf. Carrington 1987) later followed by the work of Langer $(1989,1997)$ and Kabat-Zinn $(1990,2012)$. Due to the amount of research conducted on meditation and mindfulness, scientists and clinicians stated that these states of mind have clinical implications in emotional regulation, insight and aliveness (Braboszcz et al. 2010), and for well-being and health maintenance (Hoffman 2010) as well. Mindfulness practices appear to also hold some promise for mental health clinical interventions. A study by Gilbert and Christopher (2010), in which 278 students took part, revealed that mindfulness activities significantly reduce the harmful impact of the relationship between cognition and negative emotions. According to Kaviani et al. (2011), there is evidence that mindfulness-based cognitive therapy reduces psychopathological symptoms, and a meta-analysis of 39 studies performed by Hofmann et al. (2010) shows that mindfulness-based therapies have moderate efficacy in reducing causes of anxiety and depressive symptoms. Another study conducted by Mandal et al. (2012), in which 100 college students took part, suggests that the state of mindfulness is correlated with a reduction in psychopathological symptoms and low negative affectivity.

\section{Spirituality and Mental Health}

Spirituality can be seen as a construct whose conceptualisation is complex, and in psychology, there are different positions with regard to this notion. The subject of spirituality was completely disregarded and defined as a psychopathological by-product by some authors (e.g. Ellis 1971; Freud 1961; Watson 1983), while others appear to seek to understand this aspect of the human experience and ascertain its psychological potential (e.g. Frankl 2007, 2008; Grof 2007; Jung 1999; Maslow 1994, 1998; Perls 1976). At first glance, this appears confusing, but, as we shall see, there is a consensual position about certain aspects of spirituality, which is followed by contemporary psychologists. Firstly, spirituality is not the same as religion. To not understand this is to perpetuate a certain misunderstanding which will lead to fallacious theoretical approaches-but it is understandable why this type of error prevails in some circles since, according to Zinnbauer and Pargament (2005), both spirituality and religion are reflected in human work (i.e. poetry, music, sculpture, painting). William James was one of the first psychologists to concisely define religion. James (2008) considers religion to be "the feelings, acts, and experiences of individual men in their solitude, so far as they apprehend themselves to stand in relation to whatever they may consider the divine" (p. 31). He adds that this relationship between the individual and the divine is essentially moral, physical or ritual (James 2008). However, the set of practices inherent to religion may not relate to the domain of spiritual realisation (Hood et al. 2009; Zinnbauer and Pargament 2005). Helminiak (2008) defends the separation between spirituality and the concept of the divine, assuming the latter weakens the notion of spirituality by making it vague. Spirituality itself refers to the innate capacity and the demand for a given individual to transcend him or herself (Chandler et al. 1992), and this transcendent aspect of a human being can be found both inside and outside the Self and may extend beyond the religious domain (Koenig 2010). The process of 
understanding this capacity to transcend can be as complex as it is vague-which can undermine a potential definition of spirituality. Transcendence can be regarded as an empirical and/or phenomenological way of existing in the world through self-realisation. Maslow (1998) stipulates the need for self-actualisation of the human being, in the way in which he or she understands and interacts with reality. This is in agreement with Gorsuch (2002), who states that "spirituality is the quest for understanding ourselves in relationship to our view of ultimate reality, and to live in accordance with that understanding" (p. 8). Note the absence of the concept of the divine from this definition, which was purposefully omitted; a purely ontological vision is emphasised rather than a theological perspective. Therefore, we conclude that what distinguishes spirituality from religion is the absence of references to the concept of the divine (i.e. God) and the lack of a need for rituals to bond with the divine principle (i.e. prayers) as an expression of individuality-it focuses exclusively on the transcendence of internalised life experiences. Despite the difficulty in establishing a comprehensive definition, it is possible to state that spirituality is mensurable. Examples of the main instruments of measurement are: the Daily Spiritual Experience Scale (DSES; Underwood and Teresi 2002), the Spirituality Index of Well-Being (SIWB; Frey et al. 2005) or the Spiritual Assessment Inventory (SAI, Hall and Edwards 2002). Since there are instruments for the assessment of spirituality, it can be presumed that there is a consensus regarding which domains are covered, although the conceptual difficulties are taken into account.

Most theoretical approaches are in favour of the relationship between mental health and spirituality. For Pargament et al. (2005b), spirituality: “(1) can be a part of the solution to psychological problems; (2) can be a source of problems in and of itself; (3) people want spiritually sensitive help; and (4) spirituality cannot be separated from psychotherapy" (p. 155). These considerations are the concern of the present investigation, and their validation will have a significant impact on psychological intervention. In a study conducted by Hofmann and Walach (2011), in which 895 German psychotherapists took part, it was concluded that the latter consider that spiritual guidance is relevant to 1 out of every 4 patients they attend to. Additionally, a total of $66.5 \%$ of those professionals claim that a focus on spiritual matters is essential in the higher education of a therapist (Hofmann and Walach 2011). In another study, conducted by D'Souza (2002), it can be seen that $69 \%$ of the psychiatric patients which took part believe that spiritual matters should be addressed in therapy and $67 \%$ of those patients claim that their spirituality helped them deal with psychological pain. Also regarding patients, a study by Fitchett et al. (1997), which compared psychiatric patients to other patients, showed that although there are no differences between these two groups as regards spiritual needs, psychiatric patients are reported to have diminished "spiritual well-being". In support of these data, a recent study by Sodhi and Manju (2013) that compared chronic patients to healthy individuals concluded that spirituality is significantly correlated with better mental health and that healthy subjects score higher in the spirituality and mental health compared to chronic patients.

\section{Purpose of the Study}

What we propose here, as a main goal, is to check the relationship between the spiritual outlook of patients with mental illness and their QoL. This study also seeks to confirm the nature of spiritual beliefs as associated with mindfulness, hope, diagnosis and religious confession. 


\section{Method}

\section{Participants and Procedure}

For this study, 96 patients were selected from the Magalhães Lemos EPE Hospital, from the Psychosocial Rehabilitation Services specifically. The former were selected according to their diagnosis and excluded on the basis of mental deficiency, dementia and other severe conditions. All diagnoses were made by the psychiatrist in charge, in accordance with ICD-9 classification criteria. Given that a portion of the diagnoses for these patients is provisional or vague, the patients were grouped into clusters in order to avoid bias in the data analysis. To this end, the following categories were defined: anxiety disorder; adjustment disorder; addiction disorder; mood disorder; organic mental disorder; personality disorder; psychosis; schizophrenic psychosis; and somatoform disorder. A choice was made to focus primarily on the main diagnosis and, in its absence, the secondary diagnosis - given that dealing with more than one diagnostic category is somewhat impractical because of the difficulty in standardising all possible comorbidities in the data analysis.

With the support of the nursing staff, patients were flagged and invited to the psychologist's office for a preliminary conversation, where the aim of the study was explained to them. Once the informed consent of the patient was obtained, an individual interview was conducted, lasting between 15 and $20 \mathrm{~min}$.

\section{Instruments}

Since we dealt with people who had psychiatric disorders, assessment instruments were selected with ease of application in mind - to exert low levels of cognitive and emotional stress.

A short social and demographic questionnaire consisted of questions relating to gender, age, marital status, education, occupational status, ethnic origin and religion in order to identify the main traits of these psychiatric patients.

In order to assess QoL, the WHOQOL-BREF scale was selected for this study and we used the version validated for the Portuguese population (cf. Vaz Serra et al. 2006). It is a shortened version of the WHOQOL-100 scale, containing 26 items out of the 100 featured in the full version. The domains assessed by this version are: physical, psychological, social relationships and environment. Each item score varies between 0 and 100, and higher scores mean a higher quality of life.

To assess spirituality, we used the Spirituality Rating Scale developed by Pinto and Pais-Ribeiro (2007) which has two spiritual dimensions: a vertical dimension, associated with transcendent/spiritual beliefs; and a horizontal dimension, of an existentialist nature, associated with Hope/Optimism. The scale is composed by 5 items-two for the vertical dimension and three for the horizontal dimension_and the score varies between 1 and 4 . High scores in both dimensions indicate a strong spiritual connection.

The RICH scale is a type of Likert psychometric instrument developed by Nylicek and Teixeira (2013) that evaluates components of mindfulness: Relaxation, Insight, Connection and Harmony. These items are scored between 1 ("nothing") and 10 ("completely"). 


\section{Results}

With regard to demographic sample data, it was observed that 37 of the 96 participants $(38.5 \%)$ were male and $59(61.5 \%)$ female, with ages ranging between 21 and 73 $(\mathrm{M}=50.58, \mathrm{SD}=12.533)$. The majority of patients in the sample are single $(41.7 \%)$, $27.1 \%$ are married, $20.8 \%$ are divorced, $8.3 \%$ are widowed, $1 \%$ are in a de facto union, and $1 \%$ are separated. With regard to education, $67.7 \%$ have primary education, $20.8 \%$ finished secondary school, and $11.5 \%$ completed a higher education degree. As to their occupation, $61.5 \%$ were retired, $27.1 \%$ unemployed, $2.1 \%$ active, $2.1 \%$ students and $7.3 \%$ in some other situation. With regard to the ethnic origin of the participants, $97.9 \%$ are Caucasian and $2.1 \%$ are black/African. In relation to the participants' religion, it is noted that the majority are Catholic $(80.2 \%), 7.3 \%$ are Protestant, $3.1 \%$ are atheist, $1 \%$ are Espiritistas, and $8.3 \%$ belong to other faiths. With regard to the diagnosis, the most frequent nosological category is schizophrenic psychosis $(32.3 \%)$, followed by mood disorder $(19.8 \%)$, psychosis $(15.6 \%)$, adjustment disorder $(11.5 \%)$, personality disorder $(9.4 \%)$, organic mental disorder $(5.2 \%)$, anxiety disorder $(4.2 \%)$, somatoform disorder $(1 \%)$ and addiction disorder $(1 \%)$.

With regard to the main aim of this study - to verify the existence and the nature of the relation between spiritual beliefs and quality of life-a Spearman correlation analysis was carried out. This same analysis shows that there is a statistically significant positive correlation between Spiritual Beliefs and General Quality of Life parameters $(r=.284$; $p=.005$ ); given the particular analysis of the various domains of quality of life, it is noted that the Spiritual Beliefs parameter is significantly correlated with the Physical Domain $(r=.395, p=.000)$, the Psychological Domain $(r=.341 ; p=.001)$ and the Social Relationships Domain $(r=.365, p=.000)$. There is also a positive, but not statistically significant, correlation between Beliefs and the Environment Domain $(r=.134$; $p=.194)$.

Likewise, the existence of a positive correlation, albeit a statistically significant one, was also noted between the Spiritual Beliefs and the Hope/Optimism $(r=.584 ; p=.000)$ parameters.

Also evident is a positive association between Spiritual Beliefs and all aspects of Mindfulness, one that is nonetheless weak in regard to Relaxation $(r=.226 ; p=.027)$ and Insight $(r=.252 ; p=.013)$ and moderate in relation to Contact $(r=.345 ; p=$ $.001)$ and Harmony $(r=.449 ; p=.000)$.

Table 1 shows that there are no statistically significant differences between genders in terms of Spiritual Beliefs, Hope/Optimism and Quality of Life and also shows the same for all domains of Mindfulness.

Using the Kruskal-Wallis test to compare the averages among groups of patients with specific diagnostic backgrounds, it was verified that there are no statistically significant differences between diagnostic groups in terms of Spiritual Beliefs $\left[X^{2}(8)=10.923\right.$; $p=.206]$ and in terms General Quality of Life $\left[X^{2}(8)=10.203 ; p=.251\right]$. This test suggests a lack of statistically significant differences between these same groups in terms of Relaxation $\left[X^{2}(8)=7.255 ; p=.509\right]$, Insight $\left[X^{2}(8)=10.185 ; p=.252\right]$, Contact $\left[X^{2}(8)=7.888 ; p=.444\right]$ and Harmonia $\left[X^{2}(8)=9.569 ; p=.297\right]$.

Another Kruskal-Wallis test suggests that there are statistically significant differences between religious groups in terms of Spiritual Beliefs $\left[X^{2}(4)=13.950 ; p=.007\right]$ but not in terms of General Quality of Life $\left[X^{2}(4)=5.925 ; p=.205\right]$ and all areas of 
Table 1 Differences between genders in Spiritual Beliefs, Optimism/Hope, General Quality of Life (G.QoL) and Mindfulness Domains

\begin{tabular}{lccrrr}
\hline & \multicolumn{1}{l}{ Male } & \multicolumn{1}{l}{$\begin{array}{l}\text { Female } \\
\text { M (SD) }\end{array}$} & \multicolumn{1}{l}{$T$ test } & $d f$ & Sig. (2-tailed) \\
\hline Spiritual beliefs & $2.9865(.98943)$ & $2.9775(.97148)$ & .044 & 94 & .965 \\
Optimism/hope & $2.6122(.86283)$ & $2.6056(.84518)$ & .037 & 94 & .971 \\
G. QoL & $55.4054(20.31449)$ & $49.7881(18.34939)$ & 1.401 & 94 & .165 \\
Relaxation & $5.57(1.834)$ & $5.36(2.644)$ & .426 & 94 & .671 \\
Insight & $6.16(2.511)$ & $6.22(2.936)$ & .100 & 94 & .921 \\
Contact & $5.92(2.253)$ & $5.90(2.893)$ & .037 & 94 & .971 \\
Harmony & $5.97(2.661)$ & $6.20(3.134)$ & .371 & 94 & .711 \\
\hline
\end{tabular}

Spiritual Beliefs and Optimism/Hope-higher scores indicate strong spiritual sense (Range 1-4); General Quality of Life (G.QoL) - higher scores represent better quality of life (Range 0-100); higher scores in Relaxation, Insight, Contact and Harmony indicate a strong mindful capacity (Range 1-10)

Mindfulness-Relaxation $\left[X^{2}(4)=1.659 ; p=.798\right]$, Insight $\left[X^{2}(4)=3.925 ; p=.416\right]$, Contact $\left[X^{2}(4)=3.552 ; p=.470\right]$ and Harmony $\left[X^{2}(4)=1.538 ; p=.820\right]$.

\section{Discussion}

The objective of this study was to verify how spirituality was associated with the quality of life of psychiatric patients and whether it was related to the ability to deal with their psychological problems (by assessing their capacity for mindfulness).

First, let us look at the traits of these patients. As the sample solely comprises psychiatric patients - a significant number of which suffering from severe mental illness - it is understandable that the majority of these individuals are single and not in the labour market. It was also noted that the majority of participants in this study were Caucasian with a Catholic background-which is in agreement with national statistics (Censos 2011).

Overall, the results support the notion that spiritual outlook is related to improved QoL levels and, to a certain extent, to the ability to cope with disease through mindfulness. It was observed that the greater the spiritual beliefs, the greater the general quality of life (despite the weak correlation values). Regarding the aspects of mindfulness which were assessed-including Relaxation, Insight, Contact and Harmony-these vary positively with spirituality. However, the variance scores observed in these domains are at the moderate threshold-where Contact and Harmony are more strongly correlated with the intensity of Spiritual Beliefs than Relaxation and Insight. These results agree with the data obtained by Greeson et al. (2011), where an increase in spirituality-characterised by a state of alertness and connection-is an important indicator of mindfulness and the main mechanism in an optimal mental health index.

Interestingly, it is noted that Spiritual Beliefs (i.e. perceived spirituality, not to be confused with religious views) correlated positively with Hope/Optimism, which validates the notion that spiritual people have a more positive attitude towards life. Rovers and Kocum (2010) consider that hope is one of the three facets of spirituality, and the remaining two are: faith and capacity for love. With regard to the Hope domain, the latter plays an existential role in life-one of constructing meaning-(Rovers and Kocum 2010). 
In the opinion of Park (2011), it is possible for spirituality to act in the daily construction of meaning, and according to Emmons (2003), there appears to be a positive relation between spirituality and existential issues aimed at personal goals.

It is also possible to note different levels of spiritual outlook among religious groups, suggesting that some of these patients may have an approach to spirituality that is more practical than it is attitudinal, or more methodical and dogmatic than experiential. Zinnbauer et al. (1999) are clear when they state that a spiritual quest is not synonymous with a religious (dogmatic) quest and that the latter may entail both noble and selfish intentions. Thus, it is understandable that psychiatric patients resort to spiritual ideas as a coping mechanism, even if they lack a strong spiritual outlook, and have a posture which is best characterised as religious. The data do not support the idea that "religious coping has differential effects for people from different religious affiliations" (Pargament, Ano \& Wachholtz, p. 486), since the variability noted in the perception of spirituality itself does not single-handedly validate the existence of religious coping. Also noted was the absence of changes in the expression of mindfulness skills and the individual's concept of quality of life among religious groups - this may be due to the psychiatric condition of the participants, with several inherent aspects (such as emotion and cognition) that appear to contribute towards the perception of psychological suffering. However, the literature supports the recurring use of religious coping in maintaining psychological balance, namely in the face of stress (i.e. Ano and Vasconcelles 2005) and depression (i.e. Koenig et al. 1995; Loewenthal et al. 2001) —and, for this reason, the idea of religious coping for some of these patients should not be discarded.

The data also suggest that spiritual outlook, QoL and all domains of mindfulness are evenly distributed among the groups defined based on the basis of a diagnostic. The data are not in agreement with the findings of previous studies (e.g. Goppoldova et al. 2008; Hodgson et al. 2007) which suggest changes in the psychiatric patients' QoL depending on their diagnosis. These results can be explained by the fact that all participants are patients of the Psychosocial Rehabilitation Service-a service that aims to promote a better QoL through occupational therapy, psychological counselling, nursing and psychiatric careand, consequently, it appears that changes to the patients' QoL may have been promoted to the point where it has stabilised at a regular level_-regardless of their diagnosis-justifying the absence of differences between groups. A possible reason for the homogeneity of spirituality and mindfulness in these groups may be related to the idea that specific diagnoses do not influence the way in which patients express their spiritual ideas and their capacity for mindfulness.

Our results also suggest that there are no significant differences between genders with regard to Spiritual Beliefs, QoL and Mindfulness, so data biases caused by gender stereotypes can be discarded. It is also clear that these results apply mostly to a Caucasian population due to a lack of ethnic diversity.

It was noted that the definition of spirituality can be confusing, which was the main limitation to this study. Spirituality was taken sensu latu and all participants completed the questionnaire according to their personal views-which is useful when dealing with psychiatric patients, but each of them can conceptualise their spiritual outlook in different ways, which can result in statistical variability. To correct this flaw, mindfulness was assessed in order to consolidate a potential understanding of spirituality. However, many participants considered some areas of mindfulness difficult to understand. We think that the comorbidities may be another source of statistical variability, but, as mentioned above, it is logistically difficult to standardise this information. A possible confounding variable is any degree of weakness induced by pharmacotherapy and electroconvulsive therapy- 
treatments that were used for some of the patients in this sample around the time of the assessment-which could compromise (to a certain degree) the cognitive faculties needed to fill out the questionnaires. There is also the issue of establishing the implications of these data in the spiritual coping domain, since spirituality is usually regarded as inseparable from the religious coping (i.e. Pargament 2007; Pargament et al. 2005a) and a consensus was noted among some authors, whereby spirituality and religion are held as phenomenological different concepts.

In future studies, it may be interesting to analyse how spirituality and religion relate to each other in the capacity for dealing with psychological issues through mindfulness, in different ethnic and religious groups, since the results in the present study reveal, indirectly, the possibility of religious outlooks that are regarded as coping mechanisms by many patients. Our study did not take into account the degree of psychopathology of this type of patient so it may be of interest to assess whether more "spiritual" patients suffer less psychologically.

In summary, we can state that spirituality_as a state of transcendence-inherently contains the capacity for a positive outlook on the world. Perceived QoL increases with the breadth of the individual's concept of spirituality, and the degree of optimism should be a key aspect in this association. It is unwise to conclude that having spiritual beliefs translates into a consolidated spiritual posture as it was verified this is not so. It would appear that mindfulness is a good indicator of spiritual outlook, emphasising an experiential over the practical or pragmatic notions of typical religious behaviour-enabling the independence of spirituality from the religious domain. Given the results of this study, mental health professionals should recognise the "spiritual" needs of their patients and prepare appropriate interventions in order to attend to them.

\section{References}

Ano, G. G., \& Vasconcelles, E. B. (2005). Religious coping and psychological adjustment to stress: A metaanalysis. Journal of Clinical Psychology, 61(4), 461-480. doi:10.1002/jclp.20049.

Braboszcz, C., Hahusseau, S., \& Delorme, A. (2010). Meditation and neuroscience: From basic research to clinical practice. In R. A. Carlstedt (Ed.), Handbook of integrated clinical psychology, psychiatry and behavioral medicine: Perspetives, practices, and research. New York: Springer Publishing Company LLC.

Brown, A. P., Marquis, A., \& Guiffrida, D. A. (2013). Mindfulness-based interventions in counseling. Journal of Counseling and Development, 91, 96-104.

Carrington, P. (1987). Freedom in meditation (3rd ed.). New Jersey: Pace Educational Systems.

Censos (2011) XV Recenseamento Geral da População/V Recenseamento Geral da Habitação: Resultados Definitivos Portugal. Available at http://censos.ine.pt/xportal/xmain?xpid=CENSOSandxpgid=ine_ censos_publicacao_detandcontexto=puandPUBLICACOESpub_boui=73212469andPUBLICACOESmodo= 2andselTab=tablandpcensos=61969554. Accessed 03 June 2013).

Chandler, C. K., Holden, J. M., \& Kolander, C. A. (1992). Counseling for spiritual wellness: Theory and practice. Journal of Counseling and Development, 71, 168-175. doi:10.1002/j.1556-6676.1992. tb02193.x.

Connell, J., Brazier, J., O’Cathain, A., Lloyd-Jones, M., \& Paisley, S. (2012). Quality of life of people with mental health problems: A synthesis of qualitative research. Health and Quality of Life Outcomes, 10(138), 1-16. doi:10.1186/1477-7525-10-138.

Culliford, L., \& Eagger, S. (2009). Assessing spiritual needs. In C. H. C. Cook, A. Powell, \& A. Sims (Eds.), Spirituality and psychiatry (pp. 16-38). London: RCPsych Publications.

Damianakis, T., \& Marziali, E. (2012). Older adultś response to the loss of a spouse: The function of spirituality in understanding the grieving process. Aging in Mental Health, 16(1), 57-66. doi:10.1080/ 13607863.2011.609531. 
Delgado, C. (2007). Sense of coherence, spirituality, stress and quality of life in chronic illness. Journal of Nursing Scholarship, 39(3), 229-234. doi:10.1111/j.1547-5069.2007.00173.x.

D'Souza, R. (2002). Do patients expect psychiatrists to be interested in spiritual issues? Australasian Psychiatry, 10(1), 44-47. doi:10.1046/j.1440-1665.2002.00391.x.

Ellis, A. (1971). The case against religion: A psychotherapist's view. New York: Institute for Rational Living.

Emmons, R. A. (2003). The psychology of ultimate concerns: Motivation and spirituality in personality. New York: The Gilford Press.

Fitchett, G., Burton, L. A., \& Sivan, A. B. (1997). The religious needs and resources of psychiatric inpatients. The Journal of Nervous and Mental Disease, 185(5), 320-326.

Frankl, V. E. (2007). A presença ignorada de Deus: Psicoterapia e religião. Petrópolis: Sinodal, Vozes.

Frankl, V. E. (2008). Em Busca de Sentido: Um Psicólogo num Campo de Concentração. Petrópolis: Sinodal; Vozes.

Frey, B. B., Daaleman, T. P., \& Peyton, V. (2005). Measuring a dimension of spirituality for health research: Validity of the spirituality index of well-being. Research on Aging, 27, 556-577. doi:10.1177/ 0164027505277847.

Freud, S. (1961). The future of an illusion. New York: Norton.

Gilbert, B. D., \& Christopher, M. S. (2010). Mindfulness-based attention as a moderator of the relationship between depressive affect and negative cognitions. Cognitive Therapy and Research, 34(6), 514-521. doi:10.1007/s10608-009-9282-6.

Glueck, B. C., \& Stroebel, C. F. (1975). Biofeedback and meditation in the treatment of psychiatric illnesses. Comprehensive Psychiatry, 16(4), 303-321. doi:10.1016/S0010-440X(75)80001-0.

Goppoldova, E., Dracomirecka, E., Matlova, L., \& Hajek, T. (2008). Subjective quality of life in psychiatric patients: Diagnosis and illness-specific profiles. The Canadian Journal of Psychiatry, 53(9), 587-593.

Gorsuch, R. L. (2002). Integrating psychology and spirituality?. Westport: Praeger Publishers.

Greeson, J. M., Webber, D. M., Smoski, M. J., Brantley, J. G., Ekblad, A. G., Suarez, E. C., \& Wolever, R. Q. (2011). Changes in spirituality partly explains health-related quality of life outcomes after mindfulness-based stress reduction. Journal of Behavioral Medicine, 34, 508-518. doi:10.1007/s10865-0119332-x.

Grof, S. (2007). A Psicologia do Futuro. Porto: Via Óptima.

Hall, T. W., \& Edwards, K. J. (2002). The spiritual assessment inventory: A theistic model and measure for assessing spiritual development. Journal for the Scientific Study of Religion, 41(2), 341-357. doi:10. $1111 / 1468-5906.00121$.

Helminiak, D. A. (2008). Confounding the divine and the spiritual: Challenges to a psychology of spirituality. Pastoral Psychology, 57, 161-182. doi:10.1007/s11089-008-0163-9.

Hoffman, C. (2010). Does mindfulness increase wellbeing? Journal of Holistic Health Care, 7(1), 45-48.

Hofmann, S. G., Sawyer, A. T., Witt, A. A., \& Oh, D. (2010). The effect of mindfulness-based therapy on anxiety and depression: A meta-analytic review. Journal of Consulting and Clinical Psychology, 78(2), 169-183. doi:10.1037/a0018555.

Hofmann, L., \& Walach, H. (2011). Spirituality and religiosity in psychotherapy-A representative survey among German psychotherapists. Psychotherapy Research, 21(2), 179-192. doi:10.1080/10503307. 2010.536595 .

Hodgson, Z. G., Pattison, C., Bostock, L., Murphy, T., \& Stewart, M. E. (2007). The influence of sociodemographic and illness variables on quality of life in acute psychiatric patients. Clinical Psychology and Psychiatry, 14, 269-277. doi:10.1002/cpp.536.

Hood, R. W., Hill, P. C., \& Spilka, B. (2009). The psychology of religion (4th ed.). New York: The Guilford Press.

James, W. (2008). The varieties of religious experience: A study in human nature. Maryland: Arc Manor.

Jung, C. G. (1999). Psicologia e Religião. Petrópolis: Vozes.

Kabat-Zinn, J. (1990). Full catastrophe living: Using the wisdom of your body and mind to face stress, pain, and illness. New York: Delacorte Press.

Kabat-Zinn, J. (2012). Mindfulness for beginners: Reclaming the present moment and your life. Canada: Sounds True Inc.

Kaviani, H., Javaheri, F., \& Hatami, N. (2011). Mindfulness-based cognitive therapy (MBCT) reduces depression and anxiety induced by real stressful setting in non clinical population. International Journal of Psychology and Psychological Therapy, 11(2), 285-296.

Koenig, H. G. (2010). Spirituality and mental health. International Journal of Applied Psychoanalytic Studies, 7(2), 116-122. doi:10.1002/aps.239.

Koenig, H. G., Harvey, J. C., Dan, G. B., Harold, S. K., Krishnan, K. R. R., \& Thomas, E. S. (1995). Religious coping and cognitive symptoms of elderly medical patients. Psychosomatics, 36(4), 369-375. doi:10.1016/S0033-3182(95)71646-2. 
Langer, E. J. (1989). Mindfulness. Boston: Addison-Wesley.

Langer, E. J. (1997). The power of mindful learning. Boston: Addison-Wesley.

Loewenthal, K. M., Cinnirella, M., Evdoka, G., \& Murphy, P. (2001). Faith conquers all? Beliefs about the role of religious factos in coping with depression among different cultural-religious groups in the UK. British Journal of Medical Psychology, 74(3), 293-303. doi:10.1348/000711201160993.

Mace, C. (2008). Mindfulness and the future of psychotherapy. European Psychotherapy, 8(1), $123-139$.

Mandal, S. P., Arya, Y. K., \& Pandey, R. (2012). Mental health and mindfulness: Mediational role of positive and negative affect. SIS Journal of Projective Psychiatry and Mental Health, 19, 150-159.

Maslow, A. (1994). Religions, values and peak experiences. New York: Penguin Books.

Maslow, A. (1998). Toward a psychology of being. New York: Wiley.

Masthoff, E. D., Trompenaars, F. J., Van Heck, G. L., Hodiamont, P. P., \& De Vries, J. (2006). Quality of life and psychopathology: Investigations into their relationship. Australian and New Zealand Journal of Psychiatry, 40, 333-340. doi:10.1111/j.1440-1614.2006.01799.x.

Meneses, R. F., Pais-Ribeiro, J. L., Pedro, L., Silva, I., Cardoso, H., Mendonça, D., Vilhena, E., Martins, A., \& Martins-da-Silva, A. (2013). Qualidade de Vida e Espiritualidade em Seis Doenças Crónicas. Book of Proceedings of VIII Simpósio Nacional de Investigação em Psicologia.

Nylicek, I., \& Teixeira, R. J. (2013) RICH-Relaxamento, Insight, Contacto e Harmonia. PhD Thesis, University of Aveiro, Portugal.

Oliver, J., Huxley, P., Bridges, K., \& Mohamad, H. (1997). Quality of life and mental health services. New York: Routledge.

Pargament, K. I. (2007). Spiritually integrated psychotherapy: Understanding and addressing the sacred. New York: The Guilford Press.

Pargament, K. I., Ano, G. G., \& Wachholtz, A. B. (2005a). The religious dimension of coping: Advances in theory, research, and practice. In R. F. Paloutzian \& C. L. Park (Eds.), Handbook of the psychology of religion and spirituality (pp. 479-495). New York: The Gilford Press.

Pargament, K. I., Murray-Swank, N. A., \& Tarakeshwar, N. (2005b). An empirically-based rationale for a spiritually-integrated psychotherapy. Mental Health, Religion and Culture, 8(3), 155-165. doi:10. 1080/13694670500138940.

Park, C. L. (2011). Implicit religion and the meaning making model. Implicit Religion, 14(4), 405-419.

Perls, F. (1976). The gestalt approach and eye witness to therapy. New York: Bantam Books.

Pinto, C., \& Pais-Ribeiro, J. L. (2007). Construção de uma Escala de Avaliação da Espiritualidade em Contextos de Saúde. Arquivos de Medicina, 21(2), 47-53.

Rowe, M. M., \& Allen, R. G. (2004). Spirituality as means of coping with chronic illness. American Journal of Health Studies, 19(1), 62-67.

Rovers, M., \& Kocum, L. (2010). Development of a holistic model of spirituality. Journal of Spirituality in Mental Health, 12, 2-24. doi:10.1080/19349630903495475.

Slade, M. (2010). Mental illness and well-being: The central importance of positive psychology and recovery approaches. BMC Health Services Research, 10, 26. doi:10.1186/1472-6963-10-26.

Sodhi, R., \& Manju, D. (2013). Spirituality and mental health among normal and chronic disease group. Internationa Journal of Research Studies in Psychology, 2(1), 59-68. doi:10.5861/ijrsp.2012.106.

Underwood, L. G., \& Teresi, J. A. (2002). The daily spiritual experience scale: Development, theoretical description, reliability, exploratory factor analysis, and preliminary construct validity using healthrelated data. Annals of Behavioral Medicine, 24(1), 22-33. doi:10.1207/S15324796ABM2401_04.

Vaz Serra, A., Canavarro, M., Simões, M., Pereira, M., Gameiro, S., Quartilho, M., \& Paredes, T. (2006). Estudos psicométricos do instrumento de avaliação da qualidade de vida da Organização Mundial de Saúde (WHOQOL-Bref) para português de Portugal. Psiquiatria Clínica, 27(2), 41-49.

Wallace, R. K. (1970). Physiological Effects of Transcendental Meditation. Science, 3926, 1751-1754. doi:10.1126/science.167.3926.1751.

Wallace, R. K., \& Benson, H. (1972). The physiology of meditation. Scientific American, 226(2), 84-90.

Watson, J. B. (1983). Psychology from the standpoint of a behaviorist. Dover, NH: Pinter.

WHOQOL Group. (1998). The World Health Organization quality of life assessment (WHOQOL): Development and general psychometric properties. Social Science and Medicine, 46(12), 1569-1585.

Wortman, J. H., \& Park, C. L. (2009). Religion/spirituality and changing in meaning after bereavement: qualitative evidence for the meaning making model. Journal of Loss and Trauma, 14(1), 17-34. doi:10. $1080 / 15325020802173876$.

Zinnbauer, B. J., \& Pargament, K. I. (2005). Religiousness and spirituality. In R. F. Paloutzian \& C. L. Park (Eds.), Handbook of the psychology of religion and spirituality (pp. 21-42). New York: Guilford Press.

Zinnbauer, B. J., Pargament, K. I., \& Scott, A. B. (1999). The emerging meanings of religiousness and spirituality: Problems and prospects. Journal of Personality, 67(6), 889-919. doi:10.1111/1467-6494. 00077. 